\title{
Why Should I Care?: RDA and Your Library
}

$\mathrm{B}$ y now, an American librarian would have to be living under a rock to miss hearing about Resource Description and Access (RDA). Even if you have nothing to do with cataloging or technical services, you likely have heard technical services librarians venting some of the strong emotions the new cataloging standard evokes. There are three main mindsets about RDA that I observe most commonly among librarians of any area. First, there are those who embrace the change, enthusiastically learn all they can about the new standard, and start working with RDA as soon as possible. We seem to be somewhat few and far between. Second, some librarians reluctantly make the change to RDA but try to maintain as much of the "things as they've always been" status quo in the catalog as possible. Many of these people, with time, discover the many good things RDA has to offer and become more comfortable with the changes. Finally, a large number of librarians try to avoid dealing with RDA at all costs. In some cases, this takes the form of denial, figuring that if one doesn't look too closely at those catalog records, one does not have to deal with change. In others, the resistance to RDA takes an almost militant tone. Here's the thing, though: RDA is here to stay. The change is already happening. By avoiding, resisting, or denying it, we are simply putting ourselves and our patrons at a disadvantage because we are not learning how to utilize RDA's capabilities to make our libraries even better. This essay is an opinion piece in I will discuss some ways in which I believe librarians can use RDA to improve library catalogs and services.

\section{A Bit of Background}

In the 1990s, members of the cataloging community began work on a major revision of the Anglo-American Cataloging Rules $2^{\text {nd }}$ Edition, Revised (AACR2). The modifications were necessitated by two main changes in our libraries: 1) the move from card catalogs to online public access catalogs (OPACs) and 2) the increasing variety of materials, especially electronic and online materials, which needed to be cataloged (Maxwell 2013, 1). However, as revisions progressed, it became increasingly obvious that, rather than a set of revisions, this project would result in a significantly different cataloging standard. Work on RDA (as opposed to AACR3) began in 2004 and was led by the Joint Steering Committee for Development of RDA (JSC) (JSC Archived Site, "Background"). RDA was published in 2010 and adopted by the Library of Congress and a number of other libraries in the United States in 2013.

RDA is a content standard, meaning that it provides rules about what information to include in a catalog record but does not provide instructions about the display or encoding of that information. This is meant to make RDA more flexible so it can be used in a variety of libraries and countries and with a number of different encoding standards beyond the typical Machine Readable Cataloging (MARC). RDA is based on Functional Requirements for Bibliographic Records (FRBR), published in 1998. FRBR is a conceptual model, which means that it does not provide specific rules for cataloging, which is where RDA comes in. RDA draws upon the FRBR entityrelationship model, which means that catalogers have two main goals: first, to describe the entity in hand (e.g., a book), and second, to describe the relationships that link multiple entities to one another (e.g., the relationship between a book and its author). RDA's focus on relationships is meant to reflect the way we think about information and do research, which usually involves using known entities to find unknown ones (e.g., an author's name to find other books by that author), nonlinear browsing (e.g., following links from one web document to another), and keyword searching.

In addition to providing a new way of thinking about cataloging in the Anglo-American library world, RDA is increasingly becoming an international standard. RDA Toolkit, the manual for RDA cataloging, is now available in English, Finnish, French, German, and Spanish, and translations into other languages are underway (www.rda-rsc.org). Additionally, the JSC is morphing into the RDA Steering Committee (RSC), a process that began on November 6, 2015, and will continue into 2019. The RSC will be made up of representatives from several broad regions: Africa, Asia, Europe, Latin America and the Caribbean, North America, and Oceania. This reflects the increasing international appeal of RDA as a cataloging standard. In a way, embracing RDA in our American libraries is a first step to membership in a more international library community.

The fact that most library catalogs today are electronic and many library materials are not traditional print books affected the development of RDA. Since we do not have to squeeze a bibliographic description onto a 
catalog card, catalogers now have more freedom to include extra information in records. We can also utilize authority records, controlled vocabularies, linking capabilities, and granular information encoding in new and creative ways in electronic catalogs. The fact that we are pointing our patrons to everything from books to e-books to DVDs to websites means that we have to describe these different formats carefully to create access and avoid confusion.

The new and revised rules and capabilities built into RDA are, in many cases, long and detailed and do not need to be addressed in this essay. ${ }^{1}$ Catalogers will need to learn to navigate and follow these new rules to varying degrees depending on their institution and the materials being cataloged. However, no matter how well catalogers learn these rules, and no matter how detailed their RDA records, that information will mean little if it is not utilized in the entire library. To that end, technology specialists, public services librarians, administrators, and other library workers need to have a basic understanding of the new features in RDA and their potential for improving patrons' experiences. In the following sections, I will outline a few areas that I think bear this type of scrutiny.

\section{Display}

Now that we do not have to cram a bibliographic record onto a $3 \times 5$ inch catalog card, we can add a great deal of information to our catalog records and record that information differently. RDA reflects this change in a few different ways. First, RDA does away with most (but not all!) abbreviations, especially those in Latin, making catalog records easier for our patrons to read. This is a display change that few of us really need to think about, as RDA records will simply include terms like "pages" and "illustrations" in the correct fields in our records, and our OPACs will display those terms with little to no difficulty.

Where we run into difficulty is with the numerous new fields that RDA, in partnership with MARC, has added to our catalog records. While these pieces of information can be incredibly valuable for searching and sorting records, as I will discuss later, they are often confusing for patrons (and some librarians!) to see in the catalog. For example, books are defined as having a media type of "unmediated" in RDA. This term makes sense to catalogers, and it is a controlled vocabulary term, so it also makes sense to our Integrated Library Systems (ILS) if we program them to read these fields. However, the term makes no sense to our patrons and can be distracting. Some catalogs, like that of the New York Public Library, display this information and more. Example 1 provides a screenshot of a record from the New York Public Library with the content, carrier, and media types displayed (outlined with a box). Other catalogs, like WorldCat Local, do not display this information. Example 2 is a screenshot of the WorldCat Local display of the same record in Example 1, this time without the content, carrier, and media types displayed. Deciding whether to display new RDA/MARC fields, like those for media or content type, is something that each library and/or ILS must do on its own. Weighing the needs of our patrons for more versus less information can guide us as we choose what to display in the catalog record.

$$
\text { See Figures } 1 \text { \&2 }
$$

\section{Searching and Sorting}

Because it is designed for an electronic catalog environment, RDA utilizes numerous coded fields and provides a high level of granularity. If our ILSs can take advantage of this granularity, we will be able to sort and search information in new and interesting ways. Keyword searches can already be used to find information in these new RDA/ MARC fields, but this only scratches the surface.

The new content, carrier, and media types are provided for every single RDA record. This means that everything, from books to CDs to headphones, is described more precisely than it was in an AACR2 record. The content type tells us what sort of form the information in the resource takes (for example, text or audio). The carrier type defines the object that contains that information, like a volume (book) or an audio disc (CD). The media type describes the medium needed to access the information. For books this is "unmediated" because you do not need a special device to access the information, but if you had an e-book, the media type would be "computer" because you would have to use a computer to access the book. The content, carrier, and media types are a more granular, exact take on the general material designation (GMD), which used to display in square brackets after the title of a video or audio recording, e-book, or other non-print resources. For example, "Sherlock [videorecording]" or "Little women [electronic resource]."

Many librarians are unhappy about the replacement of the GMD, as we and our patrons are used to seeing things like "electronic resource" and "sound recording" displayed with the title in our records. However, I argue that we can use the content, media, and carrier types to provide our patrons with more and clearer information. For example, rather than depending on a somewhat vague term like "videorecording," we could use the combined information from the new fields to create an icon for a DVD, which 


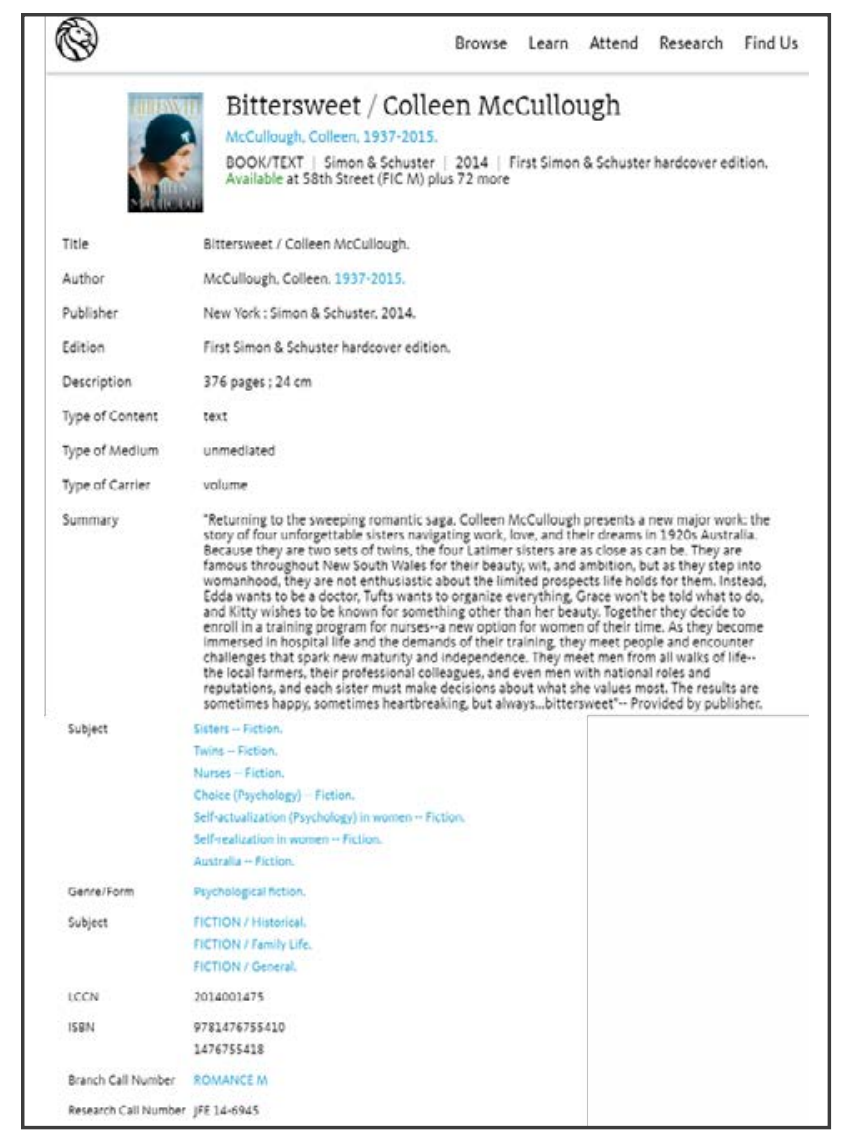

Figure 1: New York Public Library Catalog Display (with content, carrier, and media types)

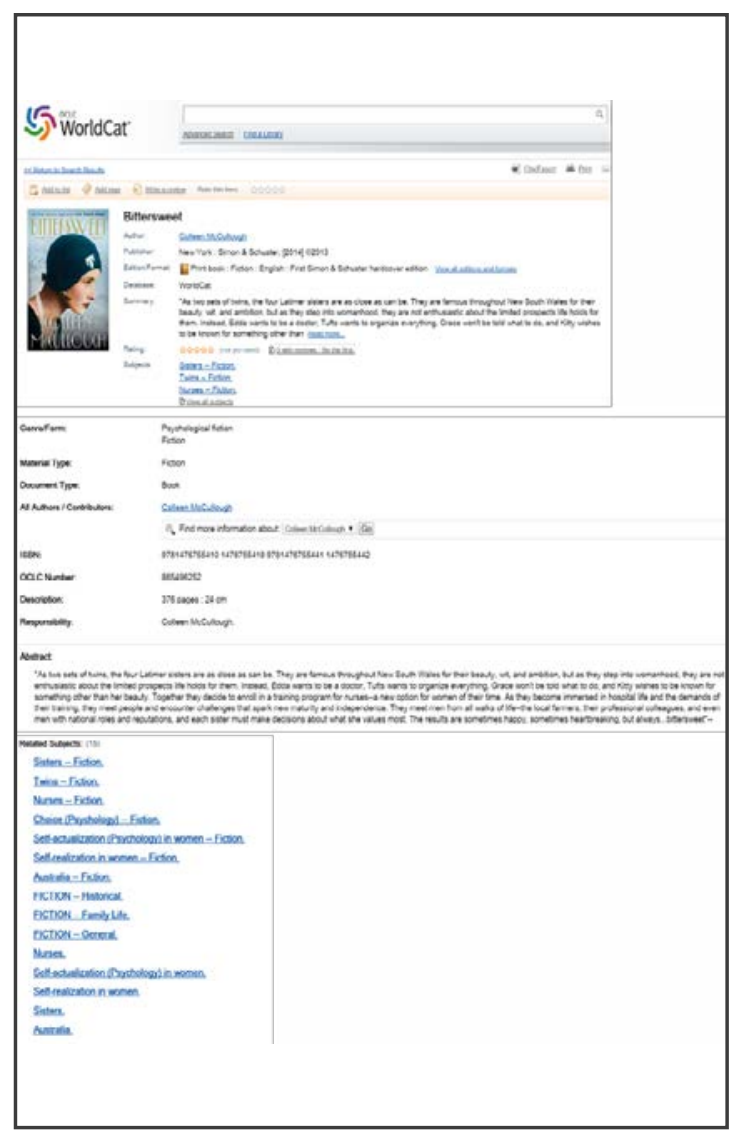

Figure 2: WorldCat Local Catalog Display (without content, carrier, and media types) could differ from that for a VHS. Similarly, the differing content types for a book on CD (spoken word) and a music CD (performed music) could allow us to differentiate between the two in searches and in our display. So even if you decide not to display terms like "unmediated" in your catalog, using them to aid in searching, sorting, and generation of display icons can be invaluable.

When it comes to non-book resources, we have even more new fields at our disposal. Some of these fields record information about the digital encoding of information on the resource, how sound is stored on the resource, and/or how video is stored on the resource. Others provide a place where we can define whether an audio recording is stereo or mono, digital or analog. Some fields also provide us with a way to differentiate between a
DVD and a Blu-Ray disc. All of this information, recorded in distinct subfields in the MARC record, can be used to search for very specific types of resources. For example, a patron could look for only Blu-Ray discs in surround sound and stereo. Similarly, this information could also be used to sort or narrow results, allowing patrons to choose e-books with smaller file sizes or streaming audio instead of CDs.

\section{Relationships}

The importance of relationships in RDA cannot be overstated. Humans tend to think of information in terms of relationships: this book is about that subject; this musical piece is performed by that musician; this review is of that book. Many relationships were informally acknowledged in AACR2. For example, we recorded the author's name in a book record, outlining the relationship between the two. However, in RDA, we become much more overt in our emphasis on recording relationships. This includes the use of relationship designators in our records and the utilization of authority records to provide linkages between resources that are related to one another, either directly or indirectly.

Using authority records as a way to link similar resources is not new. When we use an approved form of an author's name in a MARC 100 field, for example, we link that bibliographic record to all other records that include that author's name in a linking field, such as a 100 or 700 field. Where RDA differs from previous practice in this case is in its emphasis on using these types of devices to bring out relationships. While catalogers are not required to include linking fields (7XX, etc.) for all of these types of relationships, since 
RDA's creators recognized that this is a time- (and, thus, money-) consuming activity, we are encouraged to include this information if possible. This makes our records more useful in an online environment where using relationships to link between different works adds much to the searching experience.

Additionally, authority records are becoming far more detailed in RDA. I imagine a library catalog where authority records can move out of the background, allowing patrons to access that valuable information. Picture a catalog where a patron can click on an icon beside an author's name and see a pop-up of the author's date(s), profession(s), and so on. In addition to providing a link between related entities, authority records in RDA could become a bibliographic resource in and of themselves.

The use of relationship designators is new to RDA. At this time, relationship designators are really just a way to articulate why a name or title is important in a bibliographic record. This is especially helpful in records for resources like DVDs, where a large number of people may be involved in generating the final product. Rather than looking at a long list of names on records, patrons, through relationship designators, can now see why each of those people is listed. I theorize that using relationship designators as ways to add to searches would be an excellent way to take their functionality to a new level. For example, if a patron wishes to look for movies in which George Clooney has acted but does not wish to see any he directed, relationship designators might be a great way to focus a search.

Relationship designators can also come in handy when we are looking at works that are related to one another. If a movie is based on a novel, a link to the novel with a relationship designator of "Based on" could lead patrons to a new favorite book. Classical music recordings often include a number of different works by different composers, and some of those works may even be based on still other works. Outlining these relationships and providing links to other versions with other titles or different performers can be immensely helpful for our patrons. In short, the use of linking entries, such as 240 and 7XX fields, and relationship designators can lead patrons to a wealth of helpful information.

\section{The Potential of RDA}

RDA has the potential to create more functionality in our electronic catalogs. By generating more opportunities to search for a variety of types of information, to sort and display that information, and to link related resources, RDA can give our patrons a better library experience. This potential cannot be reached, however, without different library departments working together. It is not just about creating high-quality catalog records. The ILS must be designed and maintained in such a way that it utilizes the capabilities of those catalog records. Public services librarians need to understand the new and improved capabilities of RDA and how to introduce them to patrons. The transition has already begun. Many catalogers have already received training and begun creating and using high-quality RDA records. Now, all librarians should join together to try to reach the full potential of RDA cataloging in each of our libraries and as we move into the future.

\section{References}

1 For more detailed information on RDA, see the resources cited in the Suggested Readings list at the end of this essay.

\section{Suggested Readings}

Anhalt, Joy and Richard A. Stewart. "RDA Simplified." Cataloging o Classification Quarterly 50, no. 1 (2012): 33-43.

Brenndorfer, Thomas. "RDA in 10 Easy Steps.” Presentation. Available at http://www.ala.org/alcts/confevents/upcoming/webinar/ cat/ 110712

Joint Steering Committee for Development of RDA. "RDA: Resource Description and Access." Archived Site: JSC, RDA. http://www.rda-jsc. org/archivedsite/rda.html (Accessed 10 May 2016).

Joudrey, Daniel N., Arlene G. Taylor, and David P. Miller. Introduction to Cataloging and Classification. $11^{\text {th }}$ edition. Santa Barbara, California: Libraries Unlimited, 2015.

Maxwell, Robert L. Maxwell's Handbook for RDA: Resource Description \& Access. Chicago: ALA Editions, 2013.

Oliver, Chris. Introducing RDA: A Guide to the Basics. Chicago: American Library Association, 2010.

Picco, Paola and Virginia Ortiz Repiso. "The Contribution of FRBR to the Identification of Bibliographic Relationships: The New RDA-Based Ways of Representing Relationships in Catalogs." Cataloging \& Classification Quarterly 50, no.5-7 (2012): 622-640.

RDA Steering Committee. "Welcome to the RDS Website.” RSC: RDA Steering Committee. www.rda-rsc. org (Accessed 10 May 2016).

RDA Steering Committee, American Library Association, Canadian Library Association, CILIP: Chartered Institute of Library and Information Professionals. RDA Toolkit: Resource Description and Access. www.rdatoolkit.org (Accessed 10 May 2016). 